ISSN 0258-7122

Bangladesh J. Agril. Res. 39(2): 293-301, June 2014

\title{
GENOTYPE X ENVIRONMENT INTERACTION FOR GRAIN YIELD OF MAIZE (Zea mays L.) INBREDS UNDER SALINITY STRESS
}

\author{
A. BISAWAS ${ }^{1}$, U. SARKER ${ }^{2}$, B. R. BANIK ${ }^{3}$ \\ M. M. ROHMAN ${ }^{4}$ AND M. Z. A. TALUKDER ${ }^{5}$
}

\begin{abstract}
An experiment was conducted on Maize (Zea mays L.) to investigate the genotype $\times$ environment interaction for gain yield of maize inbreds under salinity stress. The objective of this study was to evaluate $\mathrm{G} \times \mathrm{E}$ interactions and yield stability in multi-environmental trials across wide ecological stress environments. Prescreened thirteen maize inbred lines collected from CYMMT, India were evaluated for phenotypic traits at different salinity conditions $(8 \mathrm{dS}$, $12 \mathrm{dS}$ and $16 \mathrm{dS}$ ) with normal environment. The environmental mean and genotypic mean ranged from 10.3 to $49.7 \mathrm{~g}$ and 10.9 to $52.8 \mathrm{~g}$, respectively. The regression coefficient $\left(b_{i}\right)$ values of these genotypes ranged from 0.44 to 1.66 . Among the genotypes P43, CZ29 and CZ33 produced higher grain yield and highly responsive under different salinity level. On the other hand considering the $\mathrm{P}_{\mathrm{i}}, \mathrm{b}_{\mathrm{i}}, \mathrm{S}^{2} \mathrm{~d}_{\mathrm{i}}$ and AMMI bi-plot analysis the genotypes E32, P29 and P35 showed almost stable performance across the different salinity conditions.
\end{abstract}

Keywords: Maize (Zea mays L.) inbred lines, genotype $\times$ environment interaction, salinity stress, grain yield, Bangladesh.

\section{Introduction}

Maize (Zea mays L.) is an important cereal crop belongs to the tribe Maydeae, of the grass family, poaceae. The plant is native to South America. Zea mays is the only species in the genus Zea with chromosome number $2 n=20$. It is the world's most widely grown cereal and is the primary staple food in many developing countries (Morris et al., 1999). Maize in Bangladesh is becoming an important crop in the rice based cropping system. In recent years maize is gaining popularity among the farmers mainly due to high yield, more economic return and versatile uses.

Among various environmental stresses, soil salinity has become a critical problem worldwide due to its dramatic effects on plant physiology and performance. Over 400 Mha across the world are affected by salinity that is about $25 \%$ of the world's total (Ghassemi et al., 1995). A major concern of agriculture in Bangladesh could thus be salinity, which is a serious threat to the sustainability

${ }^{1}$ Scientific Officer, RARS, Bangladesh Agricultural Research Institute (BARI), Jessore, ${ }^{2}$ Associate professor, Department of Genetics and Plant Breeding, Bangabandhu Sheikh Mujibur Rahman Agricultural University (BSMRAU), Gazipur, ${ }^{3}$ Director, Spice Research Centre, BARI, Shibgonj, Bogra, ${ }^{4}$ Senior Scientific Officer and ${ }^{5}$ Scientific Officer, Plant Breeding Division, BARI, Gazipur, Bangladesh. 
of crop or seed production in many parts of the country. The response of plants to excess salinity is complex and involves changes in their morphology, physiology, and metabolism. Morphologically the most typical symptom of saline injury to plant is reduction of growth (Azooz et al., 2004), which is the consequence of several physiological responses. Therefore, management and use of morphological variation under salinity condition might produce a result in selecting parental inbred to form a breeding programme for salinity resistant maize. The genotype of extra polar salinity might offer good genetic combination of better homeostasis. Maize is a $\mathrm{C}_{4}$ plant that has moderately tolerance (up to 8 $\mathrm{dS} / \mathrm{m})$. The genotype $\times$ environment interaction of maize to diverse environments is unmatched by any crop as the expansion of maize to new areas and environment still continues, as it has a range of plasticity.

Selection of best genotypes adapted to the wide range of environment specifically suitable for each of the growing seasons may help to improve the selection efficiency as well as the productivity of maize in this country under salinity stress. Therefore, to identify stable varieties or genotypes over different environments, study of genotype $\mathrm{x}$ environment $(\mathrm{G} \times \mathrm{E})$ interactions was felt essential as a preliminary step (Eberhart and Russell, 1966). It is a known fact that the genotypes performing well under a particular environment may or may not perform well over other environments due to genotype-environment interactions $(\mathrm{G} \times \mathrm{E})$. If care is not taken to select for both yield and stability of performance, one may end-up with a high yielding genotype that is suitable only for a particular environment. It is therefore, essential to develop a variety with wide adaptability in salinity areas.

\section{Materials and Method}

Prescreened thirteen genotypes of maize collected from CIMMYT, India were grown in a completely randomized design (CRD) with 3 replications at the research farm of Irrigation Division of Bangladesh Agricultural Research Institute (BARI) coordinated by Plant Breeding Division of BARI, Gazipur, Bangladesh during February to July 2012. . Seeds of each inbred were sown into the soil of plastic pots on 11 February 2012 by hand uniformly. The plastic pots were placed according to the FAO standard irrigation system for supplying the saline water. The soil was wetted by normal saline water. The seedlings were emerged six to eight days after seed sowing. The seedlings were thinned to one seedling per pot after ten days of emergence. After germination at two leaves stage irrigation was given by different concentrations (Normal water, $8 \mathrm{dS}, 12$ $\mathrm{dS}$, and $16 \mathrm{dS}$ ) of saline water in 15 days interval. Fertilizers were applied @ $120,80,80,20,5$ and $1 \mathrm{~kg} / \mathrm{ha}$ of $\mathrm{N}, \mathrm{P}_{2} \mathrm{O}_{5}, \mathrm{~K}_{2} \mathrm{O}, \mathrm{S}, \mathrm{Zn}$, and $\mathrm{B}$, respectively. Standard agronomic practices were followed (Quayyum, 1993) and plant 
protection measures were taken when required. Data were collected on grain yield and yield contributing characters. Mean data for each character was subjected to both univariate and multivariate analysis. Univariate analysis of the individual character (analysis of variance) was done by computer using MSTAT$\mathrm{C}$ software. The analysis of variance (ANOVA) was used and the G-E interaction was estimated through stability analysis using the AMMI model (Zobel et al., 1988; Durate and Zimmermann, 1991). In this procedure, the contribution of each genotype and each environment to the G-E interaction is assessed by use of the bi-plot graph display in which yield means are plotted against the scores of the first principal component of the interaction (IPCA 1). The computational program for AMMI analysis is supplied by Durate and Zimmermann (1991).

The stability parameters, regression coefficient $\left(b_{i}\right)$ and deviation from regression $\left(S^{2} d_{i}\right)$ were estimated according to Eberhart and Russel's (1966) model. Significance of differences among $b_{i}$ value and unity was tested by t-test and between $S^{2} d_{i}$ and zero by F-test.

Table 1. Sources or places of collection of 13 maize inbred lines.

\begin{tabular}{c|c|c}
\hline Genotype No. & Genotype code & Sources or places of collection \\
\hline 1 & E6 & CIMMYT, India \\
2 & E15 & CIMMYT, India \\
3 & E32 & CIMMYT, India \\
4 & E116 & CIMMYT, India \\
5 & E158 & CIMMYT, India \\
6 & P29 & CIMMYT, India \\
7 & P35 & CIMMYT , India \\
8 & P37 & CIMMYT, India \\
9 & P40 & CIMMYT, India \\
10 & P43 & CIMMYT, India \\
11 & P45 & CIMMYT, India \\
12 & CZ29 & CIMMYT, India \\
13 & CZ33 & CIMMYT, India \\
\hline
\end{tabular}

\section{Results and Discussion}

The average grain yield per plant along with the value of phenotypic index $\left(\mathrm{P}_{\mathrm{i}}\right)$, regression coefficient $\left(b_{i}\right)$ and deviation from regression $\left(S^{2} d_{i}\right)$ for grain yield per plant are presented in Table 2.

The positive and negative environmental index $\left(\mathrm{I}_{\mathrm{j}}\right)$ reflects the good or favorable and poor or unfavorable environments for this character, respectively. 
Positive environmental index represents higher grain yield and vice-versa. The environmental mean and genotypic mean ranged from 10.3 to $49.7 \mathrm{~g}$ and 10.9 to $52.8 \mathrm{~g}$, respectively.

Eight genotypes, namely E6, E15, E32, E116, E158, P29, P35, and P45 showed negative phenotypic index, while the other genotypes had positive phenotypic index for individual grain weight. Thus positive phenotypic index represented the higher grain yield and negative represented the lower grain yield among the genotypes. The genotype P43 (25.3) showed the highest phenotypic index followed by the genotype CZ29 (16.6) among the positive phenotypic index showing genotypes. Thus the $12 \mathrm{dS}$ and $16 \mathrm{dS}$ level of salinity was poor environment, while control (normal) and $8 \mathrm{dS}$ level of salinity was good environment for higher grain yield of 13 maize genotypes.

Table 2. Genotype $x$ environment interaction for grain yield per plant of 13 genotypes of maize inbred in four environments (different salinity level).

\begin{tabular}{|c|c|c|c|c|c|c|c|c|}
\hline \multirow{2}{*}{ Genotypes $\left(\mathrm{g}_{\mathrm{i}}\right)$} & \multicolumn{4}{|c|}{ Environments $\left(\mathrm{e}_{\mathrm{j}}\right)$} & \multirow{2}{*}{ Mean } & \multirow{2}{*}{$\begin{array}{c}\text { Pheno. } \\
\text { Index }\left(\mathrm{P}_{\mathrm{i}}\right)\end{array}$} & \multirow{2}{*}{$\left(b_{i}\right)$} & \multirow{2}{*}{$\left(\mathrm{S}^{2} \mathrm{~d}_{\mathrm{i}}\right)$} \\
\hline & Control & $8 \mathrm{dS}$ & $12 \mathrm{dS}$ & $16 \mathrm{dS}$ & & & & \\
\hline E6 & 37.13 & 26.60 & 16.11 & 7.30 & 21.8 & -5.7 & 0.747 & 4.11 \\
\hline E15 & 28.54 & 19.81 & 9.44 & 3.90 & 15.4 & -12.1 & $0.634 *$ & 2.42 \\
\hline E32 & 45.14 & 28.63 & 18.13 & 9.37 & 25.3 & -2.2 & $0.897 *$ & 0.40 \\
\hline E116 & 42.99 & 20.40 & 15.33 & 6.35 & 21.3 & -6.3 & 0.893 & 13.57 \\
\hline E158 & 20.33 & 13.18 & 7.51 & 2.57 & 10.9 & -16.6 & $0.444 *$ & 0.57 \\
\hline P29 & 35.81 & 21.04 & 11.67 & 4.90 & 18.4 & -9.2 & $0.780 *$ & 0.12 \\
\hline P35 & 34.46 & 19.86 & 11.06 & 5.36 & 17.7 & -9.8 & $0.738^{*}$ & 0.47 \\
\hline P37 & 61.08 & 40.69 & 21.78 & 11.59 & 33.8 & 6.3 & $1.271 *$ & 2.46 \\
\hline $\mathrm{P} 40$ & 53.54 & 35.68 & 16.83 & 9.24 & 28.8 & 1.3 & 1.155 & 4.67 \\
\hline P43 & 91.05 & 56.47 & 38.39 & 25.24 & 52.8 & 25.3 & $1.660 *$ & 5.96 \\
\hline $\mathrm{P} 45$ & 48.82 & 27.38 & 16.02 & 8.70 & 25.2 & -2.3 & 1.017 & 2.89 \\
\hline CZ29 & 75.41 & 50.30 & 30.33 & 20.37 & 44.1 & 16.6 & $1.416^{*}$ & 1.25 \\
\hline CZ33 & 71.43 & 49.27 & 30.53 & 18.44 & 42.4 & 14.9 & $1.347 *$ & 1.74 \\
\hline Mean & 49.7 & 31.5 & 18.7 & 10.3 & 27.5 & & & \\
\hline E. index $\left(I_{j}\right)$ & 22.1 & 4.0 & -8.8 & -17.3 & & & & \\
\hline
\end{tabular}

$*_{-} \mathrm{P}<0.05$

The regression coefficient $\left(b_{i}\right)$ values of these genotypes ranged from 0.44 to 1.66. These differences in $b_{i}$ values indicated that all the genotypes responded differently to different environments (i.e., sensitive to environmental changes). The regression coefficient $\left(b_{i}\right)$ of nine genotypes, namely E15, E32, E158, P29, 
P35, P37, P43, CZ29, and CZ33 was significantly different from unity which indicated high responsiveness of nine genotypes across the environments.

Among the genotypes, P43, CZ29, and CZ33 could produce higher grain yield and highly responsive under different salinity levels. This was due to the higher positive $P_{i}$ value, high $b_{i}$ value, and non-significant $S^{2} d_{i}$ value from zero. On the other hand, the genotypes E32, P29, and P35 produced moderately low yield but stable under different salinity levels due to negative phenotypic index, positive significant $b_{i}$ value close to 1 and non-significant $S^{2} d_{i}$ value from 0 . Similar type of stable genotypes was found by Prasad and Singh (1991) in pointed gourd.

The genotypes E15 and E158 produced lower grain yield $\left(\mathrm{P}_{\mathrm{i}}<0\right)$ but showed moderate stable performance by environmental fluctuations. Similar result was found by Prasad and Singh (1990) in pointed gourd. Considering the $\mathrm{P}_{\mathrm{i}}, \mathrm{b}_{\mathrm{i}}$, and $\mathrm{S}^{2} \mathrm{~d}_{\mathrm{i}}$, it was evident that all the genotypes showed different response to adaptability under differential conditions and the genotypes E32, P29 and P35 produced moderately low grain yield and stable across all poor environmental conditions. Mani and Singh (1999) assessed the yield stability in 12 maize genotypes comprising of hybrids and composites over three diverse environments.

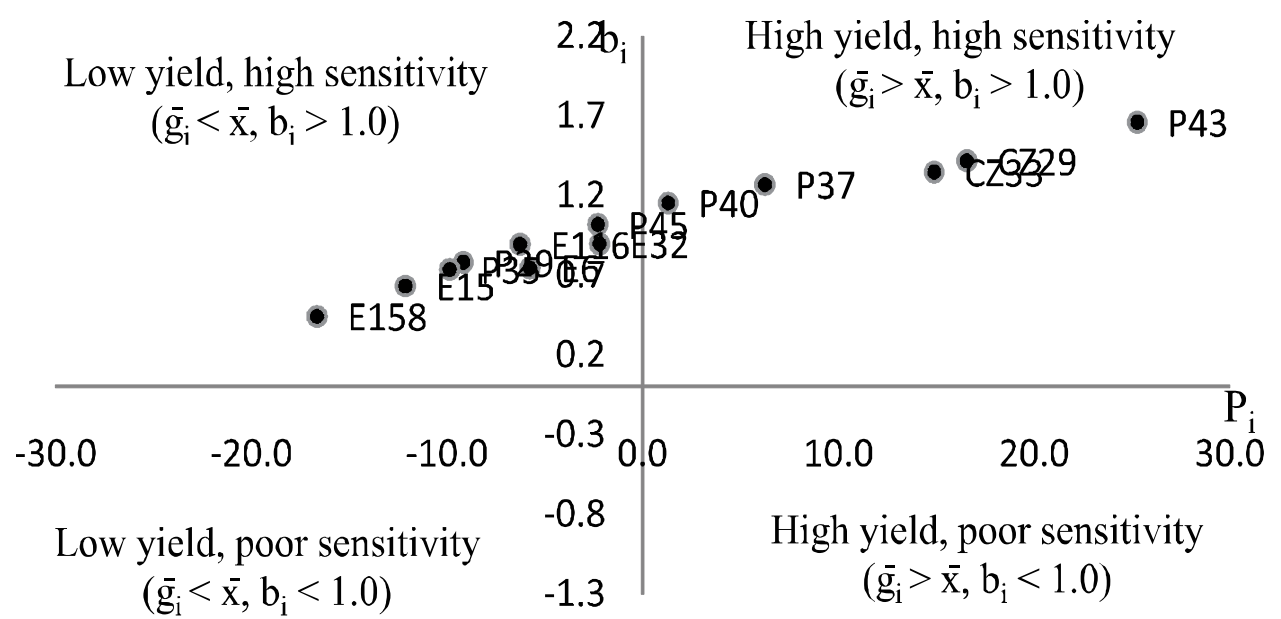

Fig 1. Adaptive specificities of 13 genotypes of maize inbred

Results of adaptive specificities of 13 genotypes are produced in Fig. 1. As per results, none of the 13 genotypes belongs to stable group. However, the genotype E32, P29, and P35 may satisfy being moderate yielder $(\mathrm{Pi}<0)$ and showing very low degree of fluctuations from linearity. Its $b_{i}$ is close to 1.0 and $S^{2} d_{i}$ is close to zero $(0)$, hence, it responds consistently well to the varying conditions. Similarly, genotypes E6, E15, E116, E158, P29, P35 and P45 showing $\mathrm{Pi}<0$ that is low yielders and genotypes P37, P40, P43, CZ29 and 
CZ33 showing $\mathrm{Pi}>0$ that is high yielders but unstable in poor environments. On the other hand, P43, CZ29, CZ33, P40, and P37 falling on right-top quarter of distribution chart indicated high yield and high response to environmental changes (Fig. 1) and rest of genotypes are falling on left-top quarter. Similar result was found by Nadagoud (2008) in maize.

\section{The AMMI model 2-biplot}

The AMMI biplot provide a visual expression of the relationship between the first interaction principal component axis (AMMI component 1) and mean of genotypes and environment (Fig.2) with the biplot up to $100 \%$ of the treatment sum of squares. The first interaction principal component axis (AMMI component 1) was highly significant and explained the interaction pattern better than other interaction axis. Balestre et al. (2009) found that the GGE biplot method to be superior to the AMMI1 graph due to more retention of GE and G + $\mathrm{GE}$ in the graph analysis.

$4.6-$

AMMI1 BIPLOT OF MAIN EFFECTS AND INTERACTIONS

\section{Co}

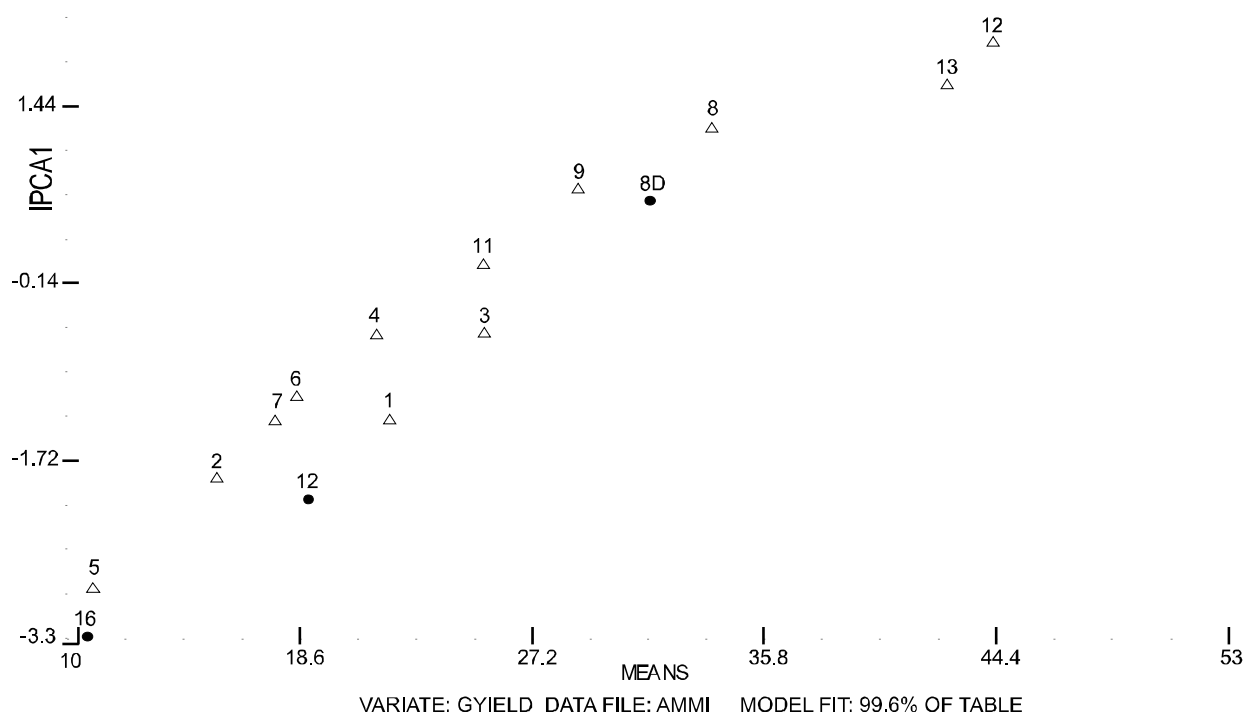

Fig. 2. Bi-plot of the first AMMI interaction (IPCA 1) score ( $\mathrm{Y}$-axis) plotted against mean yield $(\mathrm{X}$-axis) for thirteen maize genotypes. 


$$
\text { 1.9- } \quad \text { INTERACTION BIPLOT FOR THE AMMI2 MODEL }
$$

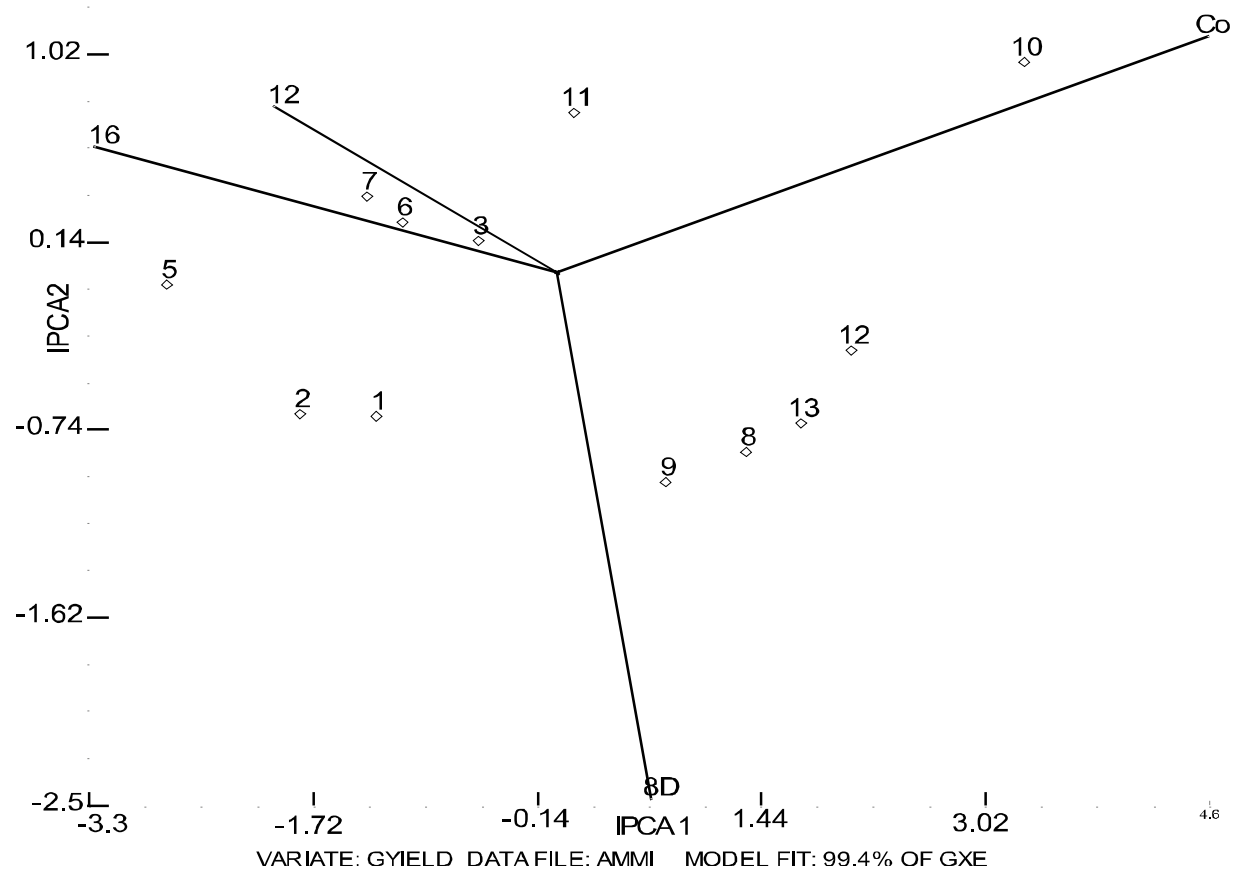

Fig. 03. Bi-plot of the first AMMI interaction (IPCA 2) score (Y-axis) plotted against AMMI interaction (IPCA 1) score ( $\mathrm{X}$-axis) for thirteen maize genotypes.

In Fig. 2, the IPCA scores for both the genotypes and the environments were plotted against the mean yield for the genotypes and the environments, respectively. By plotting both the genotypes and the environments on the same graph, the association between the genotypes and the environments can be seen clearly. The IPCA scores of a genotype in the AMMI analysis were an indication of the stability or adaptation over environments. The greater the IPCA scores, negative or positive (as it is a relative value), the more specific adaptation of a genotype to certain environments. The more the IPCA scores approximate to zero, the more stable or adaptation of a genotype in over all environments.

Considering only the IPCA 1 scores E15 (Geno. 2), E158 (Geno. 5), P43 (Geno. 10), CZ29 (Geno.12), and CZ33 (Geno.13) were unstable genotypes and not adapted to the poor environments (Fig. 02). The most stable genotypes just considering the IPCA 1 scores were E6, E32, P29, P35, and P45 (Fig. 02). Since IPCA 2 scores also play a significant role in explaining the GEI, and the IPCA 1 scores were plotted against the IPCA 2 scores to further explore adaptation (Fig. 03). According to the Fig. 03, E116 was an outlier (unstable) followed by P43, 
CZ29 and CZ33 unstable but to a lesser extent. The genotypes E6, E32, P29, and P35 showed more stable when plotted the IPCA 1 and IPCA 2 scores. Balestre et al. (2009) conducted an experiment and evaluated the phenotypic and genotypic stability and adaptability of maize hybrids using the additive main effect and multiplicative interaction (AMMI) and genotype $\mathrm{x}$ genotype-environment interaction (GGE) bi-plot models.

\section{Conclusion}

From the result, it is revealed that none of these genotypes showed significantly higher grain yield under salinity stress. Considering $P_{i}, b_{i}$, and $S^{2} d_{i}$, it is evident that all the genotypes showed different responses to adaptability under differential conditions and the genotypes E32, P29, and P35 showed almost stable across the different salinity conditions. Almost similar stability trend of the earlier three genotypes were found as per AMMI bi-plot analysis which may be used in breeding programme for obtaining higher yielding saline tolerant maize variety.

\section{Acknowledgments}

The authors would like to thank Dr. Md. Motiar Rohman, Senior Scientific Officer, Molecular Laboratory, Plant Breeding Division, BARI, Joydebpur, Bangladesh for helpful discussions.

\section{References}

Azooz, M.M., M.A. Shaddad and A.A. Abdel-Llatef. 2004. Leaf growth and $\mathrm{K}^{+} / \mathrm{Na}+$ ratio as an indication of the salt tolerance of three sorghum cultivars grown under salinity stress and IAA treatment. Acta Agron. Hungaica 52:287-296

Balestre, M., R. G. Von Pinho, J. C. Souza and R. L. Oliveira, 2009. Genotype stability and adaptability in maize based on AMMI analysis. Genet. Mol. Res. 8(4): 1311-1322.

Duarte, J. B. and M. J. de O. Zimmermann. 1991. Selection of locations for common bean germplasm evaluation. Revista de Genetica 14(3): 765-770.

Eberhart, S. A. and W. A. Russel. 1966. Stability parameters for comparing the varieties. Crop science 6: 36 - 40.

Ghassemi, F., A.J. Jakeman, H.A. Nik. 1995. Salinisation of land and water resources. Human causes, extent, management and case studies, University of New South Wales Press, Sydney, Pp. 526

Mani, V. P., N. K. Singh, G. S. Bisht And M. K. Sinha. 1999. Variability and path coefficient study in indigenous maize (Zea mays L.) germplasm. Environment and Ecology 17: 653-658.

Morris, M. L., J. Risopoulos and D. Beck. 1999. Genetic change infarmer-recycled maize (Zea mays L.) seed; a review of the evidence. CIMMYT Economic Working paper No. 99-07.Mexico, D.F., CMMYT, 1P. 
Nadagoud, V. K. 2008. Stability analysis of maize (Zea mays L.) inbred lines/introductions for yield parameters. MS Thesis, Department of Genetics and Plant Breeding, College of Agriculture, University of Agricultural Sciences, Dharwad

Prasad, S. K. and Singh, N. K., 1991, Phenotypic stability of some Indian and exotic genotypes of maize. Crop Improv. 18 : 41-45.

Quayyum, M. A. 1993. Bhuttar Chash Paddhati (in Bengali). In: Chowdhury, M. K and M. A. Islam (ed.). Bhuttar Utpadan O Babohar. Bangladesh Agricultural Research Institute, Gazipur. Pp. 43-48.

Zobel, R. W., M. J. Wright and H. G. Gauch, 1988. Statistical analysis of yield trial. Agron. J. 85: 168-170. 